\title{
Pengaruh Thinking Style Tipe II terhadap Efikasi Diri Keputusan Karier yang Dimediasi oleh Planned Happenstance Skills pada Remaja
}

\author{
Rosliyanti Sofyan \&Wahyu Indianti
}

Fakultas Psikologi Universitas Indonesia

\begin{abstract}
The aim of this study is to examine the impact of type II thinking style on career decision self-efficacy through planned happenstance skills through mediation of planned happenstance skills in adolescence. There was 720 students from three excellence schools who were participated in this quantitative study. The data were collected by using three scales: Career Decision Self-Efficacy Scale-Short Form, Thinking Style Inventory - Revised II, and Planned Happenstance Career Inventory, that have been adapted to Indonesian version by the researcher and previous researchers. The researchers were used macro PROCESS to analyzed the data. The result showed type II thinking style can affect career decision self-efficacy partially ( $\left.c=.3280, p=.0000 ; c^{\prime}=.1917, p=.0000\right)$. Based on the result of this study, we concluded when adolescents have good quality of planned happenstance skills, it can help adolescence who have type II thinking style have a good career decision selfefficacy.
\end{abstract}

Keywords: adolescence, career decision self-efficacy, planned happenstance skills, type II thinking style.

\section{Pendahuluan}

Masa remaja (adolescence) merupakan masa yang sangat penting dalam periode perkembangan individu,

Rosliyanti adalah alumni Program Studi Magister Sains Psikologi Pendidikan Universitas Indonesia (UI). Wahyu Indianti adalah Dosen Fakultas Psikologi UI. Korespondensi artikel dialamatkan ke e-mail:wahyu.indianti@ui.ac.id. karena pada masa ini individu harus dapat memahami identitas dirinya (Erikson, 1982 dalam King, 2014) agar dapat melakukan pembuatan keputusan bagi masa depannya, terutama keputusan karier (Santrock, 2013). Agar dapat dapat mengenali dirinya dengan baik, remaja perlu 
untuk melakukan ekplorasi diri. Super (1980) mentayakan bahwa eksplorasi diri remaja dimulai saat usia 15 tahun. Ketika remaja dapat melakukan proses eksplorasi diri dengan baik, maka remaja akan memiliki keyakinan diri dalam pengambilan keputusan kariernya, sebaliknya ketika remaja tidak melakukan eksplorasi diri dengan baik maka mereka akan kesulitan untuk membuat keputusan karier dengan tepat, (Sawitri, 2009).

\section{Meskipun eksplorasi dapat} menjadi sumber informasi bagi remaja dalam membuat keputusan karier, kenyataannya pembuatan keputusan karier merupakan satu tugas yang sulit bagi remaja. Mereka harus mengolah berbagai informasi internal: minat, bakat, pengetahuan akan jenis karier tertentu, identitas karier yang ingin mereka capai (Brown \& Lent, 2013; Sawitri, 2009) dan eksternal : kemajuan teknologi, informasi, dan industri memunculkan berbagai jenis karier baru yang memicu kesulitan bagi individu untuk memilih jenis karier yang tepat bagi dirinya (Stărică, 2012; Vertsberger \& Gati, 2013).

Hasil dari beberapa penelitian menyatakan bahwa kesulitan yang banyak dihadapi individu khususnya remaja dalam pembuatan keputusan karier sering terkait dengan sebuah konstruk psikologis, salah satunya efikasi diri keputusan karier (Santos \& Lam, 2017; Sawitri, 2009; Betz \& Luzzo, 1996). Efikasi diri keputusan karier adalah keyakinan diri individu dalam pembuatan keputusan karier berdasarkan beberapa kemampuan khusus yang dapat menjadi sumber pembentuk efikasi diri keputusan karier (Betz, 2000 dalam Santos \& Lam, 2017; Betz \& Luzzo, 1996). Adapun kemampuan khusus tersebut 
adalah (1) ketepatan dalam penilaian

diri, (2) mengumpulkan informasi

pekerjaan, (3) seleksi tujuan, (4)

membuat rencana untuk masa depan

dan (5) penyelesaian (Brown \& Lent,

2013; Betz \& Luzzo, 1996; Taylor \&

Betz, 1983).

Melihat kelima faktor

pembentuk efikasi diri keputusan

karier, peneliti melihat bahwa kelima

faktor tersebut terkait erat denga faktor

kognitif. Hal tersebut ditandai dengan

adanya proses pengumpulan informasi,

penilaian, hingga pembuatan

keputusan. Adapun faktor kognitif

dalam penelitian ini mengacu pada

istilah thinking style. Zhang dan

Sternberg (2005) menyatakan bahwa

thinking style merupakan

kecenderungan cara individu dalam

mengolah dan menyelesaikan

permasalahan. Berdasarkan Social

Cognitive Career Theory (SCCT) yang bersumber dari Social Cognitive

Theory (SCT) (Bandura, 1986 dalam

Lent \& Brown, 2013). Adanya interaksi antara faktor individu, perilaku, dan lingkungan akan dapat menjadi sumber pembentuk efikasi diri (Lent \& Brown, 2013). Adanya hubungan timbal balik antara person dan environment (P-E) diyakini juga dapat memengaruhi terjadinya perubahan akan minat dan preferensi individu karena adanya pengalaman belajar yang dapat memberikan kesempatan bagi individu untuk melakukan eksplorasi dan berpikir ulang mengenai kemampuannya yang didapatkan dari berbagai macam aktivitas sosial (Lent \& Brown, 2013; Vygotsky, dikutip dalam Miller, 2011).

Sternberg (1997) menyatakan bahwa thinking style dapat mempengaruhi perilaku siswa dalam pembuatan keputusan karier. Ia 
menyatakan terdapat tiga belas thinking style. Zhang dan Sternberg (2005) mengelompokkan ketiga belas thinking style ke dalam tiga tipe thinking style. Ketiga tipe thinking style tersebut memiliki karakteristik yang berbeda. Thinking style tipe I memiliki kemampuan adaptasi yang baik terhadap berbagai perubahan, fleksibel, dan mampu menyelesai masalah dengan cara yang kreatif (Timavorá \& Salaets, 2011). Thinking style tipe II cenderung rentan mengalami kecemasan karena mereka memiliki kesulitan untuk fleksibel dan beradaptasi dengan baik (Zhang, 2009), yang kemudian mengakibatkan remaja mengalami kesulitan dalam pembuatan keputusan. Ketika individu berpikiran negatif dalam proses perencanaan karier, hal tersebut dalam menurunkan efikasi dirinya (Sampson, 1996, dalam Bullock-Yowell, Andrews, \& Buzzeta, 2011) Oleh karena itu, di dalam penelitian ini peneliti berasumsi bahwa thinking style merupakan satu hal yang perlu diteliti secara lebih lanjut karena dapat mempengaruhi individu dalam pembuatan keputusan, khususnya keputusan mengenai karier masa depan.

Peneliti akan meneliti secara lebih lanjut mengenai thinking style tipe II karena adanya inkonsistensi pada hasil penelitian sebelumnya (Fan, 2016; Laensadi, in press). Hasil penelitian yang dilakukan oleh Fan (2016) mengindikasikan bahwa thinking style tipe I memiliki hubungan yang positif dan signifikan dengan efikasi diri keputusan karier, namun thinking style tipe II menunjukkan tidak terdapat hubungan yang signifikan dengan efikasi diri keputusan karier, dan thinking style tipe III hanya thinking style tipe 
internal dan eksternal saja yang memiliki hubungan yang signifikan dengan efikasi diri keputusan karier. Fan (2016) mengindikasikan thinking style tipe II tidak berkorelasi secara signifikan dengan efikasi diri keputusan karier karena adanya kemungkinan individu yang cenderung memiliki thinking style tipe II kurang dapat menunjukkan sikap kritis dalam pengolahan informasi jika dibandingkan dengan thinking style tipe I. Mereka cenderung mengolah informasi tanpa melibatkan proses berpikir kritis dan kurang berusaha untuk memberikan pemaknaan yang mendalam mengenai satu informasi, serta lebih mudah pesimis (Zhang, 2009). Sebaliknya, hasil penelitian yang dilakukan oleh Laensadi \& Salim (in press) menemukan terdapat korelasi yang positif dan signifikan antara thinking style tipe II dengan efikasi diri keputusan karier.
Adanya perbedaan hasil penelitian mengenai pengaruh thinking style tipe II terhadap efikasi diri keputusan karier mengindikasikan perlu ada satu pendekatan yang tepat bagi para remaja yang tergolong dalam individu yang cenderung termasuk ke dalam thinking style tipe II. Pendekatan tersebut ditujukan agar para remaja dapat mengembangkan diri dan beradaptasi secara kreatif untuk mengubah satu keadaan tidak terduga menjadi sebuah kesempatan belajar. Ketika remaja yang cenderung memiliki thinking style tipe II dapat adaptif di tengah berbagai perubahan, maka mereka akan dapat resilien dan lebih tertarik untuk terlibat dalam perencanaan karier masa depannya (Krumboltz, 2013).

Hasil penelitian terdahulu mengindikasikan bahwa PHS memiliki korelasi positif yang signifikan 
terhadap efikasi diri keputusan karier dan career engagement pada mahasiswa Korea (Kim, 2013; Kim, Jang, Jung, Lee, Pug, dan Lee, 2014). Hasil penelitian Ahn, Jung, Jang, Du, Lee, Rhee, Gysbers, dan Lee (2015) menyatakan bahwa tiga dari lima dimensi PHS berkaitan erat dengan munculnya pencapaian status siswa SMA yang ditunjukkan dengan adanya : kegigihan, optimisme, dan berani menghadapi risiko. Berdasarkan hasil penelitian yang dilakukan oleh para peneliti, maka dapat diketahui bahwa PHS memiliki hubungan yang positif dan signifikan dengan efikasi diri keputusan karier.

Zhang (2014) dan Sternberg (1997) menyatakan bahwa lingkungan mempengaruhi thinking style individu. Pendapat tesebut sejalan dengan pendapat Mitchell, et al. (1999) dan Krumboltz (2009) menyatakan bahwa lingkungan memberikan berbagai kesempatan bagi individu dalam melihat berbagai kesempatan bagi individu untuk belajar dari berbagai kejadian tidak terduga. Berdasarkan pendapat para ahli tersebut, peneliti berasumsi bahwa pengolahan informasi pada individu yang cenderung memiliki thinking style tipe II yang kurang dapat efektif karena adanya ketaatan yang tinggi pada peraturan, kurang mampu fleksibel, dan mudah pesimis dapat menjadi lebih adaptif dan fleksibel ketika melalui PHS sehingga efikasi diri keputusan karier remaja dapat ditingkatkan menjadi lebih baik.

\section{Kajian Pustaka}

Bandura

(2001)

mendefinisikan efikasi diri sebagai keyakinan individu akan kemampuannya untuk mengerjakan berbagai tugas. Secara lebih lanjut, 
Bandura (1986, dikutip dalam Schunk, Pintrich, \& Meece, 2010) menyatakan bahwa individu akan meyakini kemampuan diri mereka berdasarkan atas penilaian mereka akan berbagai kemampuan dirinya, dimana berbagai kemampuan tersebut sebagai alat yang dapat membantu mereka menyelesaikan tugas.

Efikasi diri dalam ranah perkembangan karier individu disebut sebagai efikasi diri pembuatan keputusan karier. Efikasi diri keputusan karier merupakan kemampuan individu dalam melakukan pembuatan keputusan karier yang bersumber dari lima kemampuan khusus, yaitu (1) penilaian diri secara tepat, (2) mengumpulkan informasi karier, (3) menyeleksi tujuan, (4) membuat perencanaan masa depan, dan (5) pemecahan masalah
(Brown \& Lent, 2013; Betz \& Luzzo, 1996; Taylor \& Betz, 1983).

Sternberg (1997) menyatakan terdapat tiga belas macam thinking style, yaitu (1) legislative, executive, (3) judicial, (4) monarchic, (5) oligarchic, (6) hierarchical, (7) anarchic, (8) local, (9) global, (10) internal, (11) external, (12) liberal, dan (13) conservative. Pada tahun 2005, Zhang dan Sternberg mengelompokkan ketiga belas thinking style ke dalam tiga tipe, yaitu mengelompokkan ketigabelas thinking style tersebut ke dalam tiga tipe, yaitu thinking style tipe I : (1) legislative, (2) judicial, (3) global, (4) liberal, dan (5) hierarchic, thinking style tipe II: (1) executive, (2) local, (3) conservative, dan (4) monarchic, dan thinking style tipe III: (1) oligarchic, (2) anarchic, (3) internal, dan (4) external. 
Planned happenstance skills merupakan perluasan dari teori belajar sosial pembuatan keputusan karier yang diajukan oleh Krumboltz (1979) (Mitchell et al., 1999). Teori tersebut menyatakan bahwa planned happenstance skills merupakan kemampuan individu untuk mengenali, membuat, dan mentransformasi sebuah kejadian tidak terduga menjadi sebuah kesempatan untuk belajar dan mengembangkan kariernya (Krumboltz, Foley, \& Cotter, 2013). Terdapat lima kemampuan agar individu dapat memiliki planned happenstance skills, yaitu (1) rasa ingin tahu, (2) kegigihan, (3) fleksibilitas, (4) optimisme, dan (5) berani mengambil risiko. Kejakdian tidak terduga berperan penting dalam perkembangan karier individu karena dapat menyediakan pengalaman sebagai sumber belajar dan mengembangkan diri (Mitchell, Levin, \& Krumboltz, 1999).

\section{Metode}

Jumlah keseluruhan responden dalam penelitian ini adalah sebanyak 1042 orang siswa yang berasal dari tiga sekolah unggulan di Jakarta. Peneliti melakukan screening data untuk memastikan kelengkapan respon partisipan dan untuk menyeleksi partisipan yang memiliki nilai rata-rata thinking style tipe II yang tinggi. Berdasarkan hasil screening jumlah partisipan menjadi 720 orang.

Diketahui jumlah siswa perempuan sebanyak $465 \quad(61,3 \%)$ orang siswa dan siswa laki-laki sebanyak 292 orang siswa $(38,5 \%)$. Berdasarkan tingkatan kelas, siswa XI sebanyak 221 orang siswa $(30,7 \%)$ dan siswa kelas XIII sebanyak 499 orang (69,3\%). Rentang usia responden dalam penelitian ini adalah $15-17$ 
tahun. Jumlah responden berusia 15 tahun sebanyak 93 orang (12,9\%), usia 16 tahun sebanyak 321 orang $(44,6 \%)$, dan usia 17 sebanyak 306 (42,5\%).

Desain penelitian ini adalah penelitian kuantitatif karena fokus pada perilaku spesifik yang dapat dengan mudah diukur (Cozby \& Bates, 2015), dan termasuk dalam jenis penelitian non-eksperimental karena peneliti tidak memberikan kontrol, perlakuan tertentu, serta manipulasi terhadap responden penelitian (Gravetter \& Forzano, 2011). Penelitian ini termasuk ke dalam jenis penelitian korelasional karena peneliti ingin menguji pengaruh antara variabel thinking style tipe II terhadap efikasi diri keputusan karier melalui mediasi planned happenstance skills pada remaja SMA.

Teknik sampling yang digunakan dalam penelitian ini adalah non-probability sampling : convenience sampling. Teknik sampling ini memungkinkan peneliti untuk menggunakan data dari sample yang sudah tersedia. Salah satu pertimbangan peneliti dalam menggunakan teknik sampling ini karena peneliti menggunakan data penelitian payung.

Efikasi diri keputusan karier diukur menggunakan Career Decision Self-Efficacy-Short Form (CDSE-SF) yang telah diadaptasi oleh Sawitri (2009) yang didasarkan pada alat ukur CDSE-SF yang disusun oleh Betz \& Luzzo (1996) dengan lima dimensi pembentuk, yaitu (1) ketepatan menilai diri sendiri; (2) mengumpulkan informasi karier; (3) menyeleksi tujuan; (4) membuat rencana masa depan; (5) kemampuan menyelesaikan masalah. Partisipan diminta untuk memberikan respon atas 21 item 
dengan rentang respon 1 sampai dengan 6 (1 Sangat Tidak Sesuai - 6 Sangat Sesuai).

Hasil analisa CFA dan Crit untuk alat ukur CDSE-SF menunjukkan terdapat 21 item yang valid karena memiliki nilai factor loading dari 0,42 sampai dengan 0,75 dengan besaran $t$-value $>1,96$, dan skor Crit memiliki rentang 0,407 0,630. Skor Cronbach's Alpha sebesar 0,906 .

Thinking style diukur dengan menggunakan Thinking Style Inventory - Revised 2 (TSI-R2) yang telah diadaptasi ke dalam bahasa Indonesia oleh Laensadi dan Salim (in press) berdasarkan alat ukur Thinking Style Inventory - Revised II yang dikembangkan oleh Stenberg, Wagner, dan Zhang (2007) yang memiliki 65 item.
Berdasarkan hasil analisis dengan menggunakan CFA dan Crit diketahui terdapat 53 item yang valid untuk mengukur thinking style tipe I, II, dan III. Jumlah item yang mengukur thinking style tipe II adalah sebanyak 14 item. Berdasarkan Hasil uji CFA dan Crit terhadap alat ukur ini menunjukkan bahwa alat ukur ini valid karena memiliki factor loading $>0,4$, dan besaran $t$-value > 1,96, serta rentang skor Crit untuk thinking style tipe II memiliki rentang dari 0,363 sampai dengan 0,569. Kemudian, berdasarkan skor Cronbcah's Alpha untuk menguji reliabilitas internal untuk thinking style tipe II adalah 0,662 (executive), 0,653 (monarchic), 0,660 (Local), dan $\quad 0,612$ (conservative).

$$
\text { PHS diukur dengan }
$$
menggunakan alat ukur Planned Happenstance Career Inventory 
(PHCI) yang telah diadaptasi ke dalam Bahasa Indonesia oleh Fatimah dan Rosliyanti (2017) dengan merujuk alat ukur PHCI yang dikembangkan oleh Kim et al., (2014) dengan total item sebanyak 25 butir. Berdasarkan hasil CFA dan Crit, diketahui bahwa terdapat 4 item yang dieliminasi karena memiliki nilai factor loading $<0,4$ dan nilai $t$-value $<1,96$. Total akhir dari item alat ukur PHCI sebanyak 21 item. menguji pengaruh antar variabel dengan menggunakan program SPSS for windows v.21.0. untuk menguji pengaruh mediasi, peneliti menggunakan macro PROCESS (Hayes, 2013).

\section{Hasil Penelitian dan Pembahasan}

Besar nilai rata-rata, standar deviasi, dan korelasi antar variabel dari ketiga variabel penelitian dapat dilihat pada Tabel 1.

Peneliti menggunakan teknik

analisa multiple regression untuk

Tabel 1. Statistik Deskriptif dan Korelasi Antar Variabel.

\begin{tabular}{|c|c|c|c|c|c|c|c|}
\hline Variabel & $\mathbf{M}$ & SD & Min & Maks & 1 & 2 & 3 \\
\hline $\begin{array}{l}\text { Efikasi diri keputusan } \\
\text { karier }\end{array}$ & 4,63 & .514 & 3 & 6 & 1 & $0,315^{* *}$ & $0,435 * *$ \\
\hline Thinking style tipe II & 4,44 & .482 & 3 & 6 & $0,315 * *$ & 1 & $0,364 * *$ \\
\hline $\begin{array}{l}\text { Planned happenstance } \\
\text { skills }\end{array}$ & 3,84 & .396 & 3 & 5 & $0,435^{* *}$ & $0,364 * *$ & 1 \\
\hline
\end{tabular}

Berdasarkan hasil uji korelasi

antar variable enelitian yang Pada

Tabel 1. menunjukkan terdapat korelasi yang signifikan antara thinking style tipe II dengan efikasi diri keputusan karier $(r=0,315, p=0,000)$, thinking style tipe II berkorelasi signifikan dengan PHS $(r=0,364 ; p=$ 0,000), dan PHS berkorelasi secara signifikan terhadap efikasi diri 
keputusan karier $(r=0,435 ; p=0,000) . \quad$ dan planned happenstance skills. Berdasarkan hasil korelasi ini, peneliti Untuk mengetahui besaran pengaruh menyimpulkan terdapat korelasi yang antar variabel penelitian dapat dilihat signifikan antara variabel thinking pada Tabel 2.

style tipe II, efikasi diri keputusan diri,

Besaran pengaruh antar variabel

Tabel 2. Matiks Pengaruh Antar Variabel Penelitian

\begin{tabular}{lllllll}
\hline Variabel & Outcome & Koefisien & $\boldsymbol{p}$ & SE & LLCI & ULCI \\
\hline TS Tipe II & EDKK & 0,1917 & 0,0000 & 0,0361 & 0,1209 & 0,2625 \\
$T S$ Tipe II & PHS & 0,3719 & 0,0000 & 0,0354 & 0,03024 & 0,4414 \\
PHS & EDKK & 0,3666 & 0,0000 & 0,0355 & 0,2969 & 0,4362 \\
\hline
\end{tabular}

Keterangan: TS Tipe II = Thinking Style Tipe II; PHS = Planned Happenstance Skills; EDKK = Efikasi diri Keputusan Karier.

Berdasarkan besaran pengaruh antar variabel penelitian pada, Tabel 2 diketahui terdapat pengaruh yang signifikan antar masing-masing variabel penelitian. Thinking style tipe II memiliki pengaruh yang signifikan terhadap efikasi diri keputusan karier $(r=0,1917 ; p=0,0000)$, thinking style tipe II berpengaruh secara signifikan terhadap planned happenstance skills(r $=0,3719 ; p=0,0000) ;$ PHS berpengaruh secara signifikan terhadap efikasi diri keputusan karier. Berdasarkan hasil ini peneliti menyimpulkan ada pengaruh yang signifikan di antara ketiga variabel penelitian.

$$
\text { Untuk mengetahui sifat }
$$
mediasi dari PHS dalam penelitian ini, peneliti membandingkan besaran nilai signifikansi dari total effect dan direct effect. Adapun perbedaan besaran nilai signifikansi dari total effect dan direct effect dapat dilihat pada Tabel 3. 
Tabel 3. Matriks Besaran Nilai Effect

\begin{tabular}{llllll}
\hline & Effect & SE & $\boldsymbol{p}$ & LLCI & ULCI \\
\hline Total Effect (c) & 0,3280 & 0,0360 & 0,0000 & 0,2574 & 0,3987 \\
Direct Effect (c') & 0,1917 & 0,0361 & 0,0000 & 0,1209 & 0,2625 \\
Indirect Effect & 0,1363 & 0,0193 & - & 0,1023 & 0,1774 \\
\hline
\end{tabular}

Berdasarkan perbandingan Berdasarkan besar nilai koefisien nilai signifikansi antara total effect $(\beta=\quad$ pengaruh dan effect dari masing$0,3280, p=0,0000)$ dan direct effect $(\beta \quad$ masing variabel penelitian, maka hasil $=0,1917, p=0,0000)$, dapat tersebut dapat dituliskan dan disimpulkan bahwa PHS dapat digambakan ke dalam gambar model memediasi secara parsial pengaruh penelitian mediasi sederhana seperti dari thinking style tipe II terhadap gambar di bawah ini:

efikasi diri keputusan karier remaja.

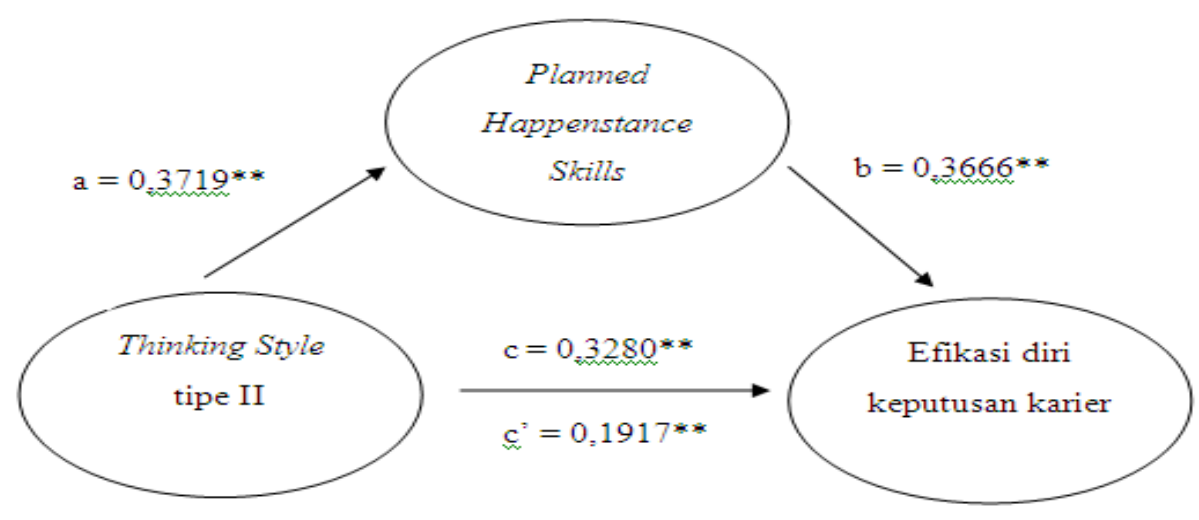

Gambar 1. Model Hasil Penelitian 
Berdasarkan uji hipotesis pada Gambar 1 didapatkan hasil bahwa thinking style tipe II dapat secara langsung mempengaruhi efikasi diri pembuatan keputusan karier secara secara signifikan $(\mathrm{c}=0,3280, p=$ 0,0000), thinking style tipe II mempengaruhi PHS secara signifikan $(a=0,371 ; p=0,000), \quad$ PHS berkorelasi secara signifikan dengan efikasi diri keputusan karier $(b=$ 0,366; $p=0,0000)$. Terakhir, diketahui bahwa terdapat pengaruh yang signifikan antara thinking style tipe II dengan efikasi diri keputusan karier (c' $=0,191 ; p=0,0000)$. Selain itu, juga diketahui bahwa efek tidak langsung dari thinking style tipe II terhadap efikasi diri keputusan karier terjadi dengan signifikan $(a b=0,136, p=$ 0,019). Dengan demikian, thinking style tipe II dapat mempengaruhi efikasi diri keputusan karier baik secara langsung maupun tidak langsung melalui PHS.

Berdasarkan hasil analisa tambahan dengan mengolah data demografi partisipan penelitian, diketahui bahwa tingkatan kelas berhubungan signifikan dengan efikasi diri keputusan karier sebesar 0,0016 ( $r$ $=0,0016 ; p<0,05)$. Adapun Untuk perbedaan nilai mean antara siswa kelas XI dan XII berdasarkan hasil uji t-test adalah sebesar 4,55 (kelas XI) dan 4,66 (kelas XII) dengan nilai taraf signifikansi sebesar $0,010(4,55<4,66$; $p<0,05)$. Jadi, dapat disimpulkan bahwa perbedaan tingkatan kelas mempengaruhi efikasi diri keputusan karier secara signifikan. 


\section{Kesimpulan dan Saran}

Dalam penelitian ini peneliti tidak menguji masing-masing thinking style di dalam thinking style tipe II (executive, local. Conservative, dan monarchic) terhadap efikasi diri keputusan karier maupun PHS pada remaja. Dengan demikian, hasil penelitian ini belum dapat memberikan gambaran secara lebih rinci mengenai pengaruh masing-masing thinking style tersebut terhadap efikasi diri keputusan karier maupun PHS. Oleh karena itu, peneliti selanjutnya dapat melakukan penelitian yang mengukur pengaruh dari masing-masing thinking style terhadap efikasi diri keputusan karier maupun PHS.

Peneliti menggunakan crosssectional study. Dengan menggunakan pendekatan penelitian cross sectional study, efek dari thinking style tipe II terhadap efikasi diri keputusan karier tidak diketahui dari waktu ke waktu, begitu pun dengan proses perkembangan PHS dalam diri remaja terhadap efikasi diri keputusan karier. Thinking style individu terbentuk melalui proses belajar yang berlangsung sepanjang rentang kehidupan (Zhang, 2012) Begitu juga dengan proses perkembangan karier individu yang berlangsung sejak usia anak-anak sampai dengan usia dewasa akhir (Super, 1980). Oleh karena itu, disain penelitian longitudinal dapat dipertimbangkan oleh peneliti selanjutnya.

Terkait dengan hasil penelitian yang menemukan bahwa PHS dapat berfungsi sebagai mediator parsial, desain penelitian intervensi terhadap PHS dapat diterapkan pada penelitian selanjutnya. Peneliti dapat melihat pengaruh mediasinya terhadap 
hubungan antara thinking style dan efikasi diri keputusan karier.

Berdasarkan hasil uji regresi diketahui terdapat pengaruh yang signifikan antara efikasi diri keputusan karier dan PHS. Peneliti menyimpulkan adanya pengaruh signifikan antara kedua variabel ini karena lokasi sekolah unggulan yang ada di Jakarta. Lokasi sekolah yang berada di kota besar dapat mempengaruhi kualitas PHS yang baik dalam diri remaja karena kemudahan akses sumber dan prasarana belajar yang memadai. Dengan demikian, penting bagi peneliti selanjutnya untuk mempertimbangkan mutu sekolah dan lokasi pengambilan data.

Agar individu yang cenderung memiliki thinking style tipe II dapat lebih fleksibel dan adaptif dalam menghadapi perubahan, guru ataupun orang tua diharapkan dapat memberikan kesempatan bagi anak untuk belajar dari kesalahan yang mereka alami. Dari kesalahan tersebut individu dapat belajar mengenai satu hal yang baru (Krumboltz \& Levin, 2010).

\section{Daftar Pustaka}

Betz N. E., \& Luzzo, D. A. (1996). Career assessment and the career decision-making selfefficacy scale. Journal of Career Assessment, 4(4), 413428.

Cohen, R. J., \& Swerdlik,M. E. (2010). Psychological testing and assessment : An introduction to tests and assessments (7th ed.). New York, NY: McGraw-Hill.

Cozby, P. C., \& Bates, S. C. (2015). Methods in behavioral research $\left(12^{\text {th }}\right.$ ed.). New York, NY: McGraw Hill.

Fan, J. (2016). The Role of thinking styles in career decisionmaking self-efficacy among university students. Thinking Skills and Creativity, 20, 63-73. 
Fatimah, D. G., \& Rosliyanti. (2017). Laporan Adaptasi dan Hasil Uji Keterbacaan Alat Ukur Planned Happenstance Career Inventory. Unpublished Manuscript.

Feist, J., Feist, G. J., \& Robert, T. - A. (2013). Theories of personality (8th ed.). New York, NY: McGraw-Hill.

Graveter, F. J., \& Forzano, L., -A., B. (2012). Research Methods for the Behavioral Sciences. Belmont, CA: Wadsworth.

Fan, J. (2016). The Role of thinking styles in career decisionmaking self-efficacy among university students. Thinking Skills and Creativity, 20, 63-73.

Fatimah, D. G., \& Rosliyanti. (2017). Laporan Adaptasi dan Hasil Uji Keterbacaan Alat Ukur Planned Happenstance Career Inventory. Unpublished Manuscript.

Graveter, F. J., \& Forzano, L., -A., B. (2012). Research Methods For the Behavioral Sciences. Belmont, CA: Wadsworth.

Hayes, A. F. (2013). Introduction to mediation, moderation, and conditional process analysis: A regression-based approach. New York, NY: Guilford.

Kim, B., Jung, H. S., Jang, H. S., Lee, B., Rhee, E. Cho, S.H., \& Lee, S. H. (2014). Construction and initial validation of the planned happenstance career inventory. The Career Development Quarterly, 62, 239-253.

King, L. A. (2014). The science of psychology. New York, NY: McGraw Hill.

Krumboltz, J. D. (2009). The happenstance learning theory. Journal of Career Assessment, 17, 135-154.

Krumboltz, J. D., \& Levin, A. L. (2010). Luck is no Accident: Making the most of happenstance in your life and career (2nd ed.). USA: Impact Publisher.

Krumboltz, J. D., Foley, P. F., \& Cotter, E. W. (2013). Applying the happenstance learning theory to involuntary career transitions. The Career Development Quarterly, 61(1), 15-26. 
Laensadi, A. M \& Salim, R.M A. (in press). Parenting styles and career decision self-efficacy: The mediating role of thinking style on gifted adolescents. Manuscript submitted for publication.

Miller, P. H. (2011). Theories of developmental psychology (5th ed.).New York, NY: Worth Publisher.

Mitchell, K. E., Levin, A. S., \& Krumboltz， J. D. (1999). Planned happenstance: Constructing unexpected career opportunities. Journal of Counseling \& Development, 77, 115-124.

Naidoo, A. V. (1998). Career maturity: A review of four decades of research. Retrieved from https://files.eric.ed.gov/fulltext /ED419145.pdf diunduh tanggal 31 Januari 2019.

Rangkuti, A. A. (2012). Teknik analisis data penelitian kuantitatif: Aplikasi dengan program SPSS. Universitas Negeri Jakarta.

Sawitri, D. R. (2009). Pengaruh status identitas dan efikasi diri keputusan karier terhadap keraguan pengambilan keputusan karir pada mahasiswa tahun pertama di Universitas Diponegoro. Jurnal Psikologi Undip, 5(2), 1-14.

Schunk, d. h., Pintrich, P. R., \& Meece, J. L. (2010). Motivation in education: Theory, research, and application (3rd ed.). New Jersey: Pearson.

Super, D. E. (1980). A life span, Lifespace approach to career development. Journal of vocational behavior, 16, 282298.

Stărică, E. C. (2012). Predictors for career indecision in adolescence. Social and Behavioral Sciences, 33, 168 172.

Sternberg, R. J. (1997). Thinking styles. New York, NY: Cambridge.

Sternberg, R. J., \& Zhang, L. -F. (2006). The nature of intellectual styles. Mahwah, NJ: Lawrence Elbaum.

Taylor, K. M., \& Betz, N. E. (1983). Applications of self-efficacy 
theory to the understanding and treatment of career indecision.

Journal of Vocational

Behavior, 22, 63-81.

Taylor, K. M., \& Betz, N. E. (1983). Applications of self-efficacy theory to the understanding and treatment of career indecision. Journal of Vocational Behavior, 22, 63-81.

Timavorá, Š., \& Salaets, H. (2011). Learning styles, motivation and cognitive flexibility in interpreter training: Selfselection and aptitude. Interpreting, 13(1), 31-52.

Vertsberger, D., \& Gati, I. (2013). The effectiveness of sources of support in career decisionmaking: A two-year follow-up. Journal of Vocational Behavior, 89, 151-161.

Yang, N., Yaung, H., Noh, H., Jang, S. H., \& Lee, B. (2017), The change of planned happenstance skills and its association with career-related variables during school-towork transition. Education Vocational Guidance, 17, 1938.

Yuwono, E. (2010, 18 Mei). Prof. Arief Rahman: Ada sepuluh ciri sekolah unggul. Republika. Diakses

dari: https://republika.co.id/berita/p endidikan/berita/10/05/18/115 906-prof-arief-rachman-adasepuluh-ciri-sekolah-unggul diakses tanggal 1 Juli 2019.

Zhang, L. -F., \& Sternberg, R. J. Culture and intellectual styles. In Li -F. Z., Robert, J. S., \& Stephen, R. (Eds.). Handbook of intellectual styles: Preferences in cognition, learning, and thinking (2012) (hlm. 131). 
Zhang, L. -F. (2009). Anxiety and thinking style. Personality and Individual Differences, 47, $347-351$.

Zhang, L. -F. (2012). Why school should care about intellectual styles. Journal of Cognitive Education and Psychology, $11(3), 256-270$.

\section{Acknowledgement:}

This study was supported by Hibah Publikasi Terindeks Internasional untuk Tugas Akhir Mahasiswa (PITTA) Universitas Indonesia that chaired by Dr. Rose Mini Agoes Salim, M.Psi, Psikolog
Zhang, L. -F., Sternberg, R. J., \& Rayner, S. (2012). Handbook of intellectual styles: Preferences in cognition, learning, and thinking. New York, NY: Springer. 